\title{
A UTILIZAÇÃO DE INCENTIVOS FISCAIS COMO ESTRATÉGIA DE FINANCIAMENTO DA INOVAÇÃO: UMA ANÁLISE ECONÔMICO-FINANCEIRA COM EMPRESAS BENEFICIADAS
}

\author{
Alex Eckert ${ }^{1}$, Fernando Luís Bertolla ${ }^{2}$
}

\section{RESUMO}

A competitividade mundial entre os países está cada dia mais acirrada, e o desenvolvimento das nações depende basicamente das empresas estabelecidas em seus territórios. Surge daí a necessidade de promover a inovação, fazendo com que o governo seja uma dos principais fomentadores de investimentos nesta área. No Brasil, a legislação específica ainda é recente, e a Lei 11.196/2005, também conhecida por Lei do Bem, é uma legislação que traz incentivos à inovação tecnológica por meio da concessão de incentivos fiscais. Diante deste contexto, o objetivo desta pesquisa foi verificar e analisar qual o comportamento de alguns índices econômico-financeiros, especialmente do faturamento e da lucratividade, nas empresas de capital aberto que se utilizaram deste incentivo, ininterruptamente, desde sua entrada em vigor no ano de 2006, até 2011, ano em que ocorreu a mais recente divulgação da listagem das empresas participantes. A partir dos critérios de seleção determinados, prosseguiu-se para uma pesquisa de natureza descritiva, utilizando a estratégia documental nas demonstrações contábeis das empresas selecionadas, cujos dados foram analisados qualitativamente. Como resultados do estudo, identificou-se que as empresas pesquisadas apresentam variações positivas em seu faturamento no período analisado. Além disso, foram identificados índices positivos de lucratividade em todas as empresas, embora fossem percebidas algumas variações entre as empresas quando estas foram analisadas individualmente.

Palavras-chave: Inovação. Empresas inovadoras. Incentivos Fiscais. Índices econômicofinanceiros.

\section{THE USE OF BRAZILIAN TAX INCENTIVES AS A STRATEGY FOR FINANCING INNOVATION: AN ANALYSIS OF ECONOMIC AND FINANCIAL INDICATORS}

\begin{abstract}
The global competition between countries is increasingly fierce, and the development of nations depends basically of companies established in their territories. There arises the need to promote innovation, causing the government to be one of the main promoters of investments in this area. In Brazil, the specific legislation is recent and Law 11.196/2005, also known as the Good Law is legislation that provides incentives for technological innovation through tax incentives. Given this context, the aim of this research was to identify and analyze what the behavior of certain financial ratios, especially the sales and profitability in publicly traded companies that used this incentive uninterruptedly since its entry into force in the year 2006 until 2011, the year in which occurred the most recent publication of the list of participating companies. From the selection criteria determined, it continued for a descriptive research, using the strategy document on the financial statements of the selected companies whose data were analyzed qualitatively. The results of the study, it was found that the companies surveyed have positive changes in revenues during the period. Furthermore, we identified
\end{abstract}

\footnotetext{
${ }^{1}$ Mestre em Administração - UFRGS, Doutorando em Administração - UCS/PUCRS, Professor da Universidade de Caxias do Sul - UCS, aeckert@ucs.br

${ }^{2}$ Mestre em Administração - UCS, Doutorando em Administração - UCS/PUCRS, Professor da Universidade de Caxias do Sul - UCS, flbertolla@ucs.br 
positive indices of profitability for all firms, although they perceived some variations between companies when they were analyzed individually.

Keywords: Innovation. Innovative companies. Tax Incentives. Financial ratios.

\section{INTRODUÇÃ̃O}

A inovação é um tema frequente quando o assunto é o desenvolvimento econômico dos países no atual contexto da economia mundial. Nesse sentido, existe praticamente um consenso entre os economistas de que o crescimento econômico dos países está associado à inovação tecnológica. Entretanto, essa máxima diminui se o assunto é como fazer inovação tecnológica e é ainda menor quando o tema da inovação tecnológica está inserido no debate sobre o desenvolvimento de países de industrialização tardia como o Brasil (ABDI, 2009).

Segundo Maximiano (1980), cada vez fica mais claro que a utilização de pesquisa e desenvolvimento científico nos países em desenvolvimento é uma das formas mais rápidas de acelerar o processo de crescimento. Entretanto, ressalta ele, para isso não basta que as empresas estabelecidas nestes países tenham capital para inovar, e sim autoconfiança e motivação para isso.

Ergas (1984) tenta explicar o motivo pelo qual alguns países inovam mais do que outros. Segundo ele, a inovação é o resultado da interação de três elementos: a (1) demanda, que proporciona o incentivo para inovar, as (2) oportunidades tecnológicas, que permitem mudar a maneira de fazer as coisas, e a (3) estrutura industrial, que conecta a demanda com as oportunidades tecnológicas. $\mathrm{O}$ autor afirma que as políticas governamentais podem alterar estes elementos e também sua interdependência.

Os principais promotores das inovações nos países são as empresas, que através dos seus setores de pesquisa e desenvolvimento (P\&D) desenvolvem suas capacidades tecnológicas que podem levar à inovação. Entretanto, Mansfield (1974) sugere que esse setor dentro das empresas é apenas parte do processo que leva à inovação tecnológica bem sucedida, e ainda, que quando estas empresas estão localizadas nos países em desenvolvimento este contexto torna-se mais complicado. Segundo ele, a capacidade da firma nacional realizar $\mathrm{P} \& \mathrm{D}$ é menor se comparada às firmas de setores semelhantes de países desenvolvidos.

O mesmo autor comenta ainda que isso se deve ao fato de que a mudança tecnológica em países em desenvolvimento possui particularidades, como a absorção de técnicas 
desenvolvidas em países líderes tecnológicos. Essa transferência se dá através da compra de máquinas e equipamentos ou de outros conhecimentos, como patentes, licenças e know-how.

Enquanto a atividade de P\&D ocorre em muitos países, o desenvolvimento e comercialização de tecnologias realmente novas tem sido historicamente concentrada em poucos países. Por exemplo, durante a década de 1970 e início de 1980, dois países, Estados Unidos e Suíça, mantiveram uma taxa de patenteamento per capita bem acima de todas as outras economias avançadas. A variação entre as economias avançadas em sua capacidade de inovar na fronteira global levanta uma questão: se inventores desenvolvem conhecimentos tecnológicos e científicos em todo o mundo, porque é que a intensidade da inovação dependem da localização? (FURMAN; PORTER; STERN, 2002)

Além de destacarem a importância potencial de $P \& D$ para a capacidade de inovação do país e desempenho em termos de crescimento, os mesmos autores sugerem que a política pública tem um papel fundamental na formação da capacidade de inovação nacional das nações. Além da disponibilização de recursos destinados a $\mathrm{P} \& \mathrm{D}$, as ações do governo deveriam contemplar também os investimentos em capital humano e os incentivos à inovação. Segundo os autores, países como Alemanha, Finlândia, Japão e Suécia, que implementaram políticas nestres três aspectos tiveram um aumento em seu nível de capacidade de inovação, principalmente nas décadas finais do século XX.

Sobre o sistema de inovação brasileiro, existem vários estudos identificando o seu caráter incompleto e imaturo. A imaturidade do sistema pode ser identificada quando são comparados indicadores de ciência e tecnologia com países representativos de outras categorias tecnológicas. Uma das formas de analisar o grau de maturidade do sistema de inovação brasileiro é avaliar a estrutura industrial brasileira, onde é percebida uma desagregação, pois há estudos indicando que apenas $8,1 \%$ da receita líquida da indústria brasileira provêm de setores classificados como de alta tecnologia. (ALBUQUERQUE; et al, 2002)

De acordo com Arbache (2005), há indicativos de que a inovação afeta positivamente a produtividade da empresa. Segundo ele, as empresas que lançam novos produtos tecnológicos no mercado têm uma produtividade média bem superior em relação àquelas que não inovam. No Brasil, o que pode ser percebido é um aumento de intensidade de 
direcionamento de recursos em $\mathrm{P} \& \mathrm{D}$, demonstrando um estágio inicial de investimentos nesta área.

Como consequência do aumento da produtividade das empresas apresenta-se uma maior lucratividade. Reis (2008) aponta que quando as empresas introduzem inovações no mercado, ela alteram o próprio contexto de mercado. Embora exista um risco associado a introdução de uma inovação no mercado, as empresas assumem este risco na expectativa de obter vantagens competitivas em relação às demais, na forma de lucros diferenciados.

No contexto brasileiro, existem diversos obstáculos à inovação das empresas nacionais. Em estudo publicado na primeira década do século XXI, Cruz e Mello (2006) apontam seis aspectos, quais sejam: os altos custos, o risco econômico, a escassez de financiamentos, a falta de trabalhados qualificados, a falta de informação e a dificuldade em adotar padrões.

Apesar dos entraves, o Brasil vem fazendo, nos últimos anos, esforços no sentido de de melhorar seu desempenho nos três tipos de atividades de inovação (criação, aquisição, uso). De diferentes maneiras, o país está tentando alavancar um sistema de inovação eficaz, com apoio para a atividade de pesquisadores em tempo integral, medidas para o estabelecimentos de acordos de licenciamento e compra de bens capital, facilidade de acesso a crédito por parte de pequenas empresas, entre outros (RODRIGUEZ; DAHLMAN; SALMI, 2008).

Além dos citados, existe outro esforço por parte do governo brasileiro que busca desenvolver a inovação nas empresas, que são os incentivos fiscais. Esse incentivos são políticas destinadas ao setor privado da economia que, segundo Cruz e Mello (2006), se caracterizam, dentre outros, em deduzir no imposto de renda os gastos com pesquisa e desenvolvimento e com pagamento de direitos autorais para uso de marcas e patentes, além de assitência técnica e científica.

A Lei ${ }^{\circ} 1.196 / 2005$, também conhecida como a Lei do Bem, entrou em vigor com o objetivo de simplificar a solicitação de isenção fiscal pelas empresas que desenvolverem internamente inovações tecnológicas, seja na concepção de novos produtos, seja no processo de fabricação e agregação de novas funcionalidades ou características ao produto ou processo (RODRIGUEZ; DAHLMAN; SALMI, 2008). 
Diante deste contexto, a questão de pesquisa para o presente estudo é: Qual o comportamento econômico-financeiro, especialmente do faturamento e da lucratividade, entre as empresas brasileiras de capital aberto que se utilizaram do incentivo fiscal da Lei $\mathrm{n}^{\circ}$ 1.196/2005 (Lei do Bem)? O objetivo da pesquisa é verificar e analisar o comportamento de alguns índices econômico-financeiros entre as empresas de capital aberto que se utilizaram deste incentivo ininterruptamente, desde sua entrada em vigor no ano de 2006, até 2011, ano em que ocorreu a mais recente divulgação da listagem das empresas participantes.

\section{INOVAÇÃO}

A inovação pode ser tanto o desenvolvimento de um novo produto, processo ou um novo serviço introduzido em um produto ou no mercado. Trata-se de um processo que envolve desde o desenvolvimento de algo, sua introdução no mercado, sua distribuição e uso pelo consumidor. A inovação pode ser tanto de produto, quanto de processo ou organizacional (LUNDVALL, 2002).

Para Schumpeter (1982), a inovação é o processo resultante da introdução de um novo produto com o qual os consumidores ainda não estão acostumados, da aplicação um novo método de produção, da abertura de um novo mercado, da utilização de uma nova fonte de suprimento de matérias primas ou insumos e, por fim, da execução da nova organização de qualquer indústria. Assim, uma inovação é considerada bem sucedida caso possa ser vendida para os consumidores em uma quantidade e a um preço que proporcione lucro.

Já a OCDE (2007), através do Manual de Oslo, diz que a inovação não gera necessariamente um impacto no produto final. Por exemplo, a inovação pode ser a execução de novos processos de produção ou o aperfeiçoamento nas técnicas, nos equipamentos e ou em softwares da produção, o quais trazem benefícios no processo de produção que podem resultar no aumento da produtividade e na redução de custos.

De uma forma mais simplificada, a inovação é algo novo que agregue valor social ou riqueza, que gere lucro. Ela se refere a coisas diferentes e novas que nascem a partir do que já está posto (conhecimento), do que está disponível por aí (informação) e do que ainda vai surgir (criatividade) (ZAWISLAK, 2008). A inovação pode ser vista como uma idéia, prática ou objeto que é percebida como nova por um indivíduo ou outra unidade de adoção 
(ROGERS, 1995). É uma invenção que atingiu a fase de introdução no mercado como uma solução original para uma necessidade ou desejo (UTTERBACK, 1971)

Nelson (2000) defende que as empresas necessitam de um conjunto de competências ou capacitações centrais para realizar inovações de forma que consigam sobreviver no longo prazo. Estas capacidades dinâmicas representam podem ser compreendidas como as melhores escolhas da empresa partir de conjuntos de capacitações definidas. Segundo o autor, as diferentes estratégias, estruturas e capacitações centrais constituem os motivos pelos quais as empresas se diferenciam umas das outras.

A teoria das capacidades dinâmicas é um conjunto de atributos que analisa as fontes e os métodos de criação e captura de riqueza por empresas que operam em ambientes de rápidas mudanças. Assim, o desenvolvimento dessas empresas depende sobremaneira da capacidade que elas têm de aperfeiçoar internamente os seus processos tecnológicos, organizacionais e gerenciais (TEECE; PISANO; SCHUEN, 1997).

De acordo com Motohashi (1998), praticamente existe consenso sobre a percepção de que a inovação promove o progresso tecnológico, que por sua vez aumenta a produtividade, a demanda por novos produtos, além de melhorar a eficiência, fazendo da inovação um elemento essencial para o crescimento.

Dosi (1982) propões que a inovação tem quatro propriedades fundamentais: (1) a incerteza, que remete à existência de problemas tecnoeconômicos cujas soluções são desconhecidas, (2) a crescente dependência das novas oportunidades tecnológicas no conhecimento, (3) a crescente formalização das atividades de pesquisa e desenvolvimento e sua execução dentro das empresas e (4) o learn by doing, onde a aprendizagem ocorre por meio de atividades informais de solução de problemas.

\section{O CONTEXTO DA INOVAÇÃO NO BRASIL}

Mesmo antes da última década do Século XX, o Brasil já havia construído um sistema nacional de ciência, tecnologia e inovação bem avançado, se comparado a outros países da América Latina. O governo direcionava investimentos sistemáticos em educação e pesquisa, fazendo com que a produção científica brasileira ampliasse significativamente sua presença no cenário internacional e acumulasse conhecimentos em algumas áreas como por exemplo, na agropecuária, na saúde e na exploração de petróleo, e estes investimentos já estavam 
trazendo retorno social e econômico. Entretanto, esse sistema apresentava diversos problemas, dentre os quais detacam-se a pequena participação das instituições privadas, as restrições para a importação de tecnologias estrangeiras e a excessiva centralização das ações governamentais na esfera federal (DAHLMAN; FRISCHTAK, 1993).

Silva e Melo (2001) destacam que na década de democratização do país, nos anos 80, ocorreram vários impactos positivos no setor a área de ciência, tecnologia e inovação: explicitou-se a demanda, valorizou-se o papel da comunidade acadêmica no processo de construção da sociedade, e, como grande marco no em termos de reformas institucionais, criou-se em 1985 o Ministério da Ciência e Tecnologia (MCT), expressando a importância política que o país começava a dar a esta área.

Segundo Oliveira (2002), a construção Sistema Brasileiro de Inovação, da maneira como ele se apresenta atualmente, resultou basicamente da ocorrência de três eventos principais: (1) a promulgação da Constituição Federal de 1988, (2) a política de abertura econômica e de maior inserção do país no mercado internacional da década de 1990 e (3) a realização pelo MCT, em 1991, de um importante estudo sobre a política de Ciência e Tecnologia existente no Brasil naquele momento.

Diversos estudos empíricos apresentam características de empresas brasileiras inseridas neste contexto inovativo. Kannebley Júnior, Porto e Pazzelo (2003), por exemplo, identificaram que as principais diferenças entre empresas inovadoras e não-inovadoras brasileiras dizem respeito à orientação exportadora, ao tamanho da firma, à origem do capital e ao setor a que pertencem. Os autores concluíram que empresas exportadoras e as de origem estrangeira do capital são as grandes responsáveis pelo dinamismo tecnológico nacional.

Braga e Willmore (1990), por sua vez, investigaram os determinantes da decisão de uma empresa brasileira realizar três tipos de esforço tecnológico: (1) desenvolver novos produtos e gastar em $\mathrm{P} \& \mathrm{D}$, (2) adotar medidas de racionalização da produção e (3) adqurir tecnologia no exterior. Os resultados indicam que a probabilidade de desenvolver novos produtos aumenta quando: o capital da empresa é de propriedade estrangeira, as empresas são maiores, existe diversificação da produção, as empresas têm lucro e exportam.

Em termos de políticas públicas, há um grande número de iniciativas por parte dos governos dos países desenvolvidos que buscam apoiar a criação de pequenas empresas de alta 
tecnologia, a transferência de conhecimentos entre universidades, centros de pesquisa e empresas. Como resultados dessas iniciativas governamentais tem-se diversos casos de sucesso em termos de inovação. (LUNDVALL, 1992). No Brasil, embora os empresários reconheçam a importância de se buscar auxílio fora da sua própria empresa, uma pequena parcela consegue realizar parcerias com universidades e centros de pesquisa (TURCHI, 2013).

Trazendo as políticas públicas de incentivo à inovação para o contexto brasileiro, com a entrada em vigor da Lei de Inovação (Lei $n^{\circ}$ 10.973/2004), o Brasil passou a contar com um novo instrumento de fomento à inovação e à pesquisa científica e tecnológica no ambiente produtivo, com vistas à capacitação e ao alcance da autonomia tecnológica e ao desenvolvimento industrial do país. Essa legislação criou dispositivos legais para a transferência de tecnologia gerada nas instituições científicas e tecnológicas, a incubação de empresas no espaço público, a valorização da propriedade intelectual, o desenvolvimento tecnológico e a geração de produtos e processos inovadores, dentre outros.

No ano seguinte, entrou em vigor a Lei $\mathrm{n}^{\circ} 11.196 / 2005$, também conhecida como a Lei do Bem, a qual traz incentivos fiscais para as empresas que desenvolverem internamente inovações tecnológicas, seja na concepção de novos produtos, seja no processo de fabricação e agregação de novas funcionalidades ou características ao produto ou processo. A referida legislação dispõe, em seu capítulo III, sobre quais são estes benefícios que as empresas poderão usufruir. De maneira resumida, esses benefícios se apresentam na forma de:

- dedução do valor correspondente aos dispêndios realizados no período com pesquisa tecnológica e desenvolvimento de inovação tecnológica no valor a recolher do IRPJ (Imposto sobre a Renda da Pessoa Jurídica);

- redução de 50\% do IPI (Imposto sobre Produtos Industrializados) incidente sobre equipamentos, máquinas, aparelhos e instrumentos destinados à pesquisa e ao desenvolvimento tecnológico;

- depreciação integral, no próprio ano da aquisição, de máquinas e equipamentos novos, destinados à utilização nas atividades de pesquisa tecnológica e desenvolvimento de inovação tecnológica, o que resulta em redução do IRPJ e da CSLL (Contribuição Social sobre o Lucro Líquido);

- amortização acelerada, no período de apuração em que forem efetuados, dos dispêndios relativos à aquisição de bens intangíveis, vinculados 
exclusivamente às atividades de pesquisa tecnológica e desenvolvimento de inovação tecnológica, o que resulta na diminuição de IRPJ;

- redução a zero da alíquota do IRRF (Iimposto de Renda retido na fonte) nas remessas efetuadas para o exterior destinadas ao registro e manutenção de marcas, patentes e cultivares.

A Lei do Bem, e o Decreto $n^{0}$ 5.798/2006, que regulamentou a utilização dos incentivos fiscais, preveem que todas as empresas beneficiárias dos incentivos ficam obrigadas a prestar ao Ministério da Ciência, Tecnologia e Inovação (MCTI), por meio eletrônico, um formulário de prestação de contas contendo as informações sobre os seus programas de pesquisa tecnológica e desenvolvimento de inovação tecnológica, até 31 de julho do ano seguinte. Além disso, essas empresas devem fazer uma segregação contábil de todos os dispêndios em contas específicas, além de arquivar todos os documentos comprobatórios destes gastos.

A quantidade de empresas que estão se beneficiando de Lei do Bem está crescendo anualmente, fato que se verifica através do Relatório Anual de Aproveitamento de Incentivos da Lei 11.196/2005. Constata-se que no primeiro ano em que a lei passou a vigorar (2006), o número de empresas a se utilizar do benefício era de apenas 130, e seis anos depois, a quantidade de empresas já atingiu 767. Segundo o próprio relatório divulgado pelo MCTI, provavelmente este aumento se deu por conta de uma maior divulgação da lei, bem como pelo aperfeiçoamento no próprio formulário de prestação de contas (MCTI; 2013).

\section{4. ÍNDICES ECONÔMICO-FINANCEIROS}

Certamente, o investimento em inovações tecnológicas e a utilização dos incentivos que fomentam este tipo de inovação nas empresas geram para elas benefícios financeiros e econômicos, tendo em vista a redução de suas despesas com IRPJ e CSLL e consequente aumento da sua lucratividade. Assim, a evolução econômica-financeira das empresas pode ser observada nas suas demonstrações contábeis através das análises de balanço, que segundo Iudícibus (2009), não é nada mais que o acompanhamento sistemático ao longo do tempo de valores quantitativos que constam nestas demonstrações. Segundo o autor, “ [...] a necessidade de analisar demonstrações contábeis é pelo menos tão antiga quanto a própria origem de tais peças" (p.1). 
As demonstrações contábeis das empresas são o resultado das informações lançadas na contabilidade, a qual tem a função primordial de registar as variações quantitativas e qualitativas no patrimônio das entidades, de modo que atendam às necessidades de seus usuários. (ECKERT, 2013)

Existem duas formas básicas de análise das demostrações contábeis: a vertical e a horizontal. A primeira delas é a comparação que se faz entre os valores e/ou percentuais de uma mesma conta ou grupo de contas, de um mesmo período. A segunda, por sua vez, também é um processo comparativo, mas de dois ou mais períodos. (MARION, 2012).

Gitman (1997) explica que os índices calculados através das análises de balanço são utilizados para comparar o desempenho e a situação de uma empresa com outras empresas, ou consigo mesma ao longo do tempo. Matarazzo (2003) complementa que existem índices que são utilizados por praticamente todos os analistas, e dentre eles destacam-se a participação de capitais de terceiros, rentabilidade do patrimônio líquido, liquidez corrente, dentre outros.

Outro conjunto de índices relevantes nas análises de balanços são os índices de rentabilidade, que medem o resultado da atividade da empresa. A rentabilidade mede a capacidade econômica da empresa, ou seja, evidencia o grau de êxito obtido na geração de um lucro em razão do capital nela investido. Dentre os índices de rentabilidade, destaca-se análise da Margem Líquida (ML), a qual mede a porcentagem da receita de vendas que restou após serem descontados todos os custos, as despesas e os impostos, indicando a lucratividade da empresa sobre suas vendas líquidas. O índice da ML é obtido através da divisão do Lucro Líquido (LL) pela Receita Operacional Líquida (ROL) (CAMARGO, 2009).

\section{ASPECTOS METODOLÓGICOS}

Quanto aos objetivos, o método empregado nesta pesquisa é de natureza descritiva. Cooper e Schindler (2003) afirmam que pesquisas com objetivo de estudo descritivo aplicamse para descrever o comportamento dos fenômenos ou características da população alvo, mensuram e ou quantificam os eventos. Para Barros e Lehfeld (2007), neste tipo de pesquisa não há a interferência do pesquisador, cabendo a ele apenas descrever o objeto da pesquisa, bem como descobrir a frequência com que determinado fenômeno ocorre, suas caractersíticas, natureza, causas relações e conexões com outros fenômenos. 
Já em relação aos procedimentos técnicos, a estratégia utilizada nesta pesquisa é classificada como documental. Para Martins e Theóphilo (2007), a utilização de documentos como fonte de dados, informaçõese evidências caracteriza uma pesquisa como documental, desde que as fontes sejam primárias. Godoy (1995), por sua vez, sustenta que pesquisa documental nada mais é do que o exame de materiais de natureza diversa, que ainda não receberam um tratamento analítico, ou que podem ser reexaminados nas busca por novas interpretações.

Quanto à forma de abordagem do problema, trata-se de uma pesquisa qualitativa. Mascarenhas (2012) afirma que esse tipo de pesquisa é usado quando existe a intenção de descrever o objeto de estudo com profundidade, permitindo que o pesquisador fique à vontade para desenvolver o estudo da forma que lhe parecer mais adequada. Segundo Diehl e Tatim (2004), estudos qualitativos podem descrever a complexidade de determinado problema e a interação de certas variáveis, bem como compreender e classificar os processos dinâmicos vividos por grupos sociais, e ainda contribuir no processo de mudança de determinado grupo e possibilitar, em maior nível de profundidade, o entendimento das particularidades do comportamento dos indivíduos.

As empresas analisadas neste estudo foram selecionadas por etapas. Inicialmente, através do site do MCTI, foram analisados os seis relatórios anuais da Lei do Bem, de 2006 a 2011, buscando identificar neles a existência de empresas que que se utilizaram, em todos os anos, dos incentivos fiscais dessa lei. Nessa primeira etapa foram identificadas 27 empresas. A partir dessa listagem, segregou-se as empresas de capital aberto que negociam ações na BM\&FBOVESPA, visto que apenas estas são obrigadas a publicar suas demonstrações contábeis. Assim, chegou-se a um total de 7 empresas: sendo três do setor de energia elétrica, duas fabricantes de material rodoviário, uma fabricante de produtos de uso pessoal e outra fabricante de cigarros e fumo.

Buscando minimizar a possibilidade de um viés na pesquisa, foram excluídas da análise as 3 empresas de energia elétrica, visto que estas são vinculadas a agências reguladoras e possuem regras específicas em inovação através de investimentos obrigatórios em P\&D (Lei $n^{\circ}$ 9.991/2000). Assim, a análise final foi realizada com 4 empresas, cujos dados financeiros referentes à ROL e LL foram obtidos a partir das demonstrações contábeis 
publicadas no site da BM\&FBOVESPA. Para o cálculo dos índices foi utilizado o software Microsoft Office Excel 2007.

\section{APRESENTAÇÃO DOS RESULTADOS E ANÁLISE}

A partir do relatado no tópico anterior, as empresas que terão suas demonstrações contábeis alvo de análise são as descritas no Quadro 1. Em seguida, são apresentadas algumas características com base nas informações disponibilizadas nos websites das referidas empresas.

Quadro 1: Empresas analisadas

\begin{tabular}{|l|l|l|l|l|}
\hline Empresa & CNPJ & Localização & UF & Setor \\
\hline FRAS-LE S/A & $88.610 .126 / 0001-29$ & CAXIAS DO SUL & RS & Material Rodoviário \\
\hline MARCOPOLO S/A & $88.611 .835 / 0001-29$ & CAXIAS DO SUL & RS & Material Rodoviário \\
\hline NATURA COSMÉTICOS S/A & $71.673 .990 / 0001-77$ & ITAPECERICA DA SERRA & SP & Produtos de Uso Pessoal \\
\hline SOUZA CRUZ S/A & $33.009 .911 / 0001-39$ & RIO DE JANEIRO & RJ & Cigarros e Fumo \\
\hline
\end{tabular}

Fonte: elaborado pelos autores

A primeira das empresas a ser analisada é a Fras-le, empresa fundada em 1954 que tem como atividade a produção de materiais de fricção, mais especificamente lonas e pastilhas de freio para veículos, além de revestimentos de embreagem, dentre outros. Possui fábricas no Brasil (Rio Grande do Sul), nos Estados Unidos (Alabama) e na China (Pinghu), além de centros de distribuição na Argentina, na Europa e Estados Unidos.

Já a Marcopolo foi fundada no ano de 1949 na cidade de Caxias do Sul, Rio Grande do Sul, com o nome de Nicola \& Cia. Ltda. Em 1971, graças ao sucesso alcançado com o lançamento do ônibus "Marcopolo", passou a denominar-se Marcopolo S.A. É uma empresa que tem seu nome ligado à história do transporte de passageiros, pois já produziu mais de 350 mil ônibus em suas fábricas no Brasil e exterior, contando com uma força de trabalho atual de mais de 22 mil colaboradores.

A Natura é uma empresa brasileira de cosméticos, presente em sete países da América Latina e na França. No Brasil, é a indústria líder no mercado de cosméticos, fragrâncias e higiene pessoal, assim como no setor da venda direta. Desde 2004 é uma companhia de capital aberto, com ações listadas no Novo Mercado, o mais alto nível de governança corporativa da BM\&FBOVESPA. 
A última das empresas foco de análise é a Souza Cruz. Fundada em 1903, no Rio de Janeiro, é líder no mercado nacional de cigarros, atuando em todo o ciclo do produto, desde a produção e o processamento de fumo, até a fabricação e a distribuição de cigarros. É subsidiária da British American Tobacco, o mais tradicional dos grupos de tabaco, com marcas comercializadas em 180 países.

Em termos de faturamento no período analisado, quando comparado com o ano imediatamente anterior, percebe-se que as empresas vêm tendo um crescimento médio de $9 \%$ na sua Receita Operacional Líquida (ROL), conforme demonstrado na Tabela 1:

Tabela 1: Variação da ROL em relação ao ano anterior

\begin{tabular}{|c|c|c|c|c|c|c|}
\hline & 2007 & 2008 & 2009 & 2010 & 2011 & Média \\
\hline FRAS-LE & $7 \%$ & $3 \%$ & $-1 \%$ & $19 \%$ & $7 \%$ & $7 \%$ \\
\hline MARCOPOLO & $22 \%$ & $19 \%$ & $-19 \%$ & $44 \%$ & $14 \%$ & $16 \%$ \\
\hline NATURA & $11 \%$ & $18 \%$ & $17 \%$ & $21 \%$ & $-24 \%$ & $9 \%$ \\
\hline SOUZA CRUZ & $14 \%$ & $7 \%$ & $5 \%$ & $1 \%$ & $1 \%$ & $6 \%$ \\
\hline
\end{tabular}

Chama atenção que a maior variação positiva no período analisado foi da empresa Marcopolo, que no ano de 2010 teve uma ROL 44\% maior do que no ano imediatamente anterior. Entretanto, é possível que essa variação tenha sido decorrente da queda na ROL de 2009, possivelmente afetada pela crise mundial dos subprimes.

Quando analisados individualmente os índices de rentabilidade, mais especificamente a Margem Líquida (ML), percebe-se que há discrepâncias entre as quatro empresas. A Fras-le, por exemplo, apresenta valores positivos em todos os anos analisados, conforme pode ser verificado na Figura 1.

Figura 1: Margem Líquida da empresa Fras-le 2006-2011

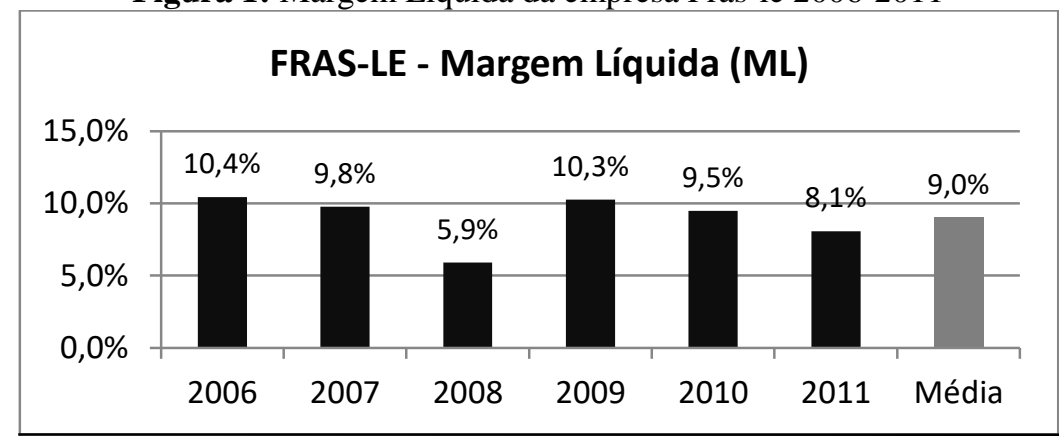

Fonte: elaborado pelos autores 
A ML média da Fras-le no período foi de 9\%, com desvio padrão de 1,7\%. Caso fosse ignorado o ano de 2008, quando a empresa teve seu menor índice de rentabilidade $(5,9 \%)$, a ML média dos seis anos teria sido de 9,6\%.

A próxima empresa alvo de análise também é ramo de material rodoviário. Trata-se da Marcopolo, que também apresentou ML positiva em todos os anos verificados. Entretanto, chama atenção que a ML média do período (de 7,5 \%, com desvio padrão de 2,1\%) ficou inferior se comparada com a média da Fras-le, que é de 9\%. Os índices referenciados constam da Figura 2.

Figura 2: Margem Líquida da empresa Marcopolo 2006-2011

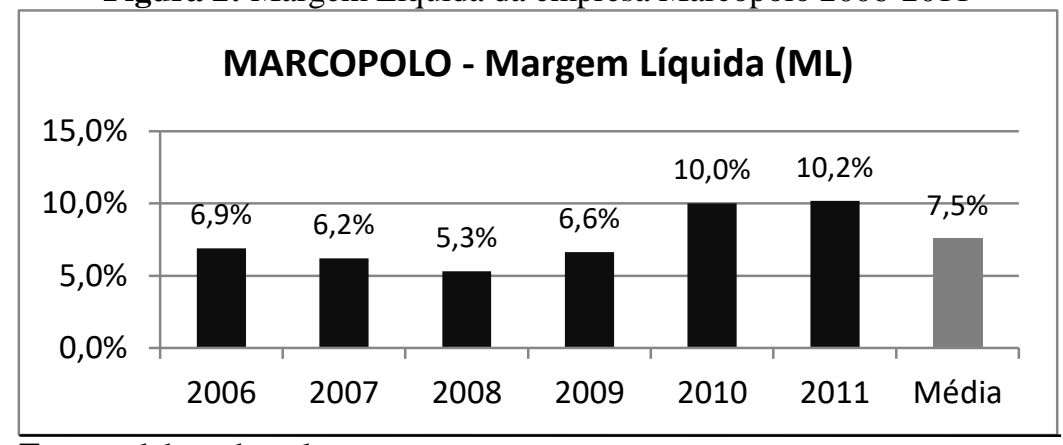

Fonte: elaborado pelos autores

Outro aspecto que chama atenção quando analisados os índices da Marcopolo é que nos últimos dois anos analisados, 2010 e 2011, percebe-se uma variação significativa da ML em relação aos quatro anos anteriores. Se fossem tratados isoladamente, os últimos dois anos representariam uma ML superior a $10 \%$.

A terceira das empresas objeto desta análise é a Natura. Observando-se os índices de ML anuais, percebe-se que estes não são, em nenhum dos anos analisados, inferiores a 14,3\%. A média da rentabilidade desta empresa nos seis anos foi de $16,3 \%$, conforme ilustrado na Figura 3, com desvio padrão de 2,6\%. 
Figura 3: Margem Líquida da empresa Natura 2006-2011

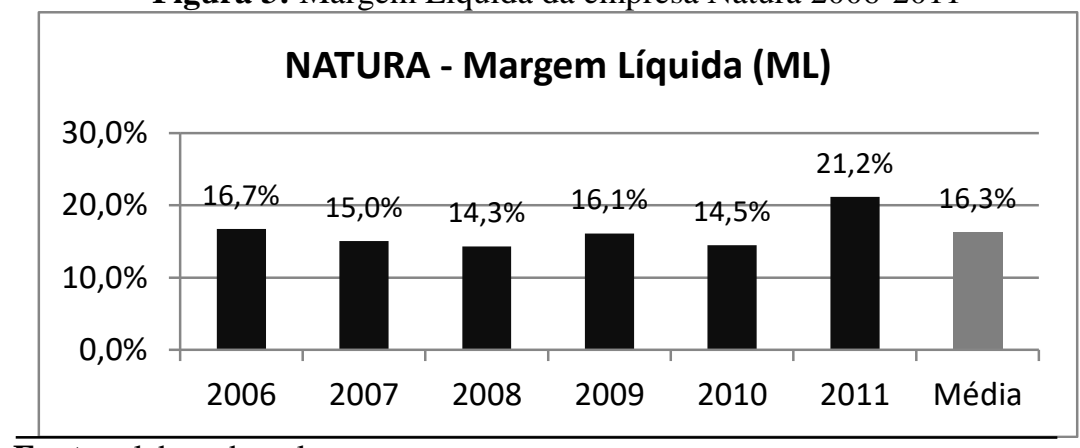

Fonte: elaborado pelos autores

Em termos de ML, se comparados os índices da Natura com os da Fras-le e da Marcopolo, considerando tratar-se de empresas de segmentos diferentes, um aspecto merece consideração. Mesmo o menor índice de ML encontrado na Natura (14,3\% no ano de 2008) é superior aos melhores índices apresentados pelas duas primeiras: 10,4\% da Fras-le em 2006 e 10,2\% da Marcopolo em 2011.

A Souza Cruz, por sua vez, dentre as empresas analisadas foi a que apresentou os maiores índices em termos de ML. Considerando a análise dos exercícios de 2006 a 2011, os cálculos indicaram uma rentabilidade média de $23,8 \%$, com desvio padrão de $4,1 \%$. A Figura 4 indica que, nesse período, a empresa obteve o melhor índice no ano de 2011, quando apresentou uma ML próxima de 30\%.

Figura 4: Margem Líquida da empresa Souza Cruz 2006-2011

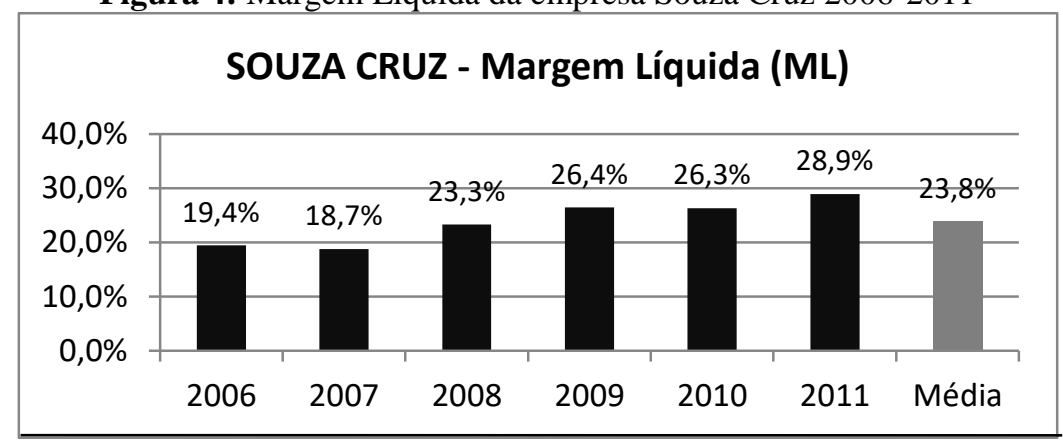

Fonte: elaborado pelos autores

Depois de realizada a análise entre os índices das quatro empresas objeto deste estudo, é realizado um comparativo entre os percentuais encontrados nestas empresas com dois indicadores externos, apresentados na Figura 5. O primeiro indicador é o Ibovespa, o qual reflete o desempenho médio das cotações e os retornos das ações que compõem o mercado de ações brasileiro (BM\&FBOVESPA, 2013). O rendimento médio deste indicador no período foi de $16,8 \%$, com desvio padrão de 45,1\%. Comparando este percentual com a ML média das 
empresas analisadas, apenas a Souza Cruz superou o Ibovespa, embora a Natura tenha ficado apenas $0,5 \%$ abaixo do mesmo.

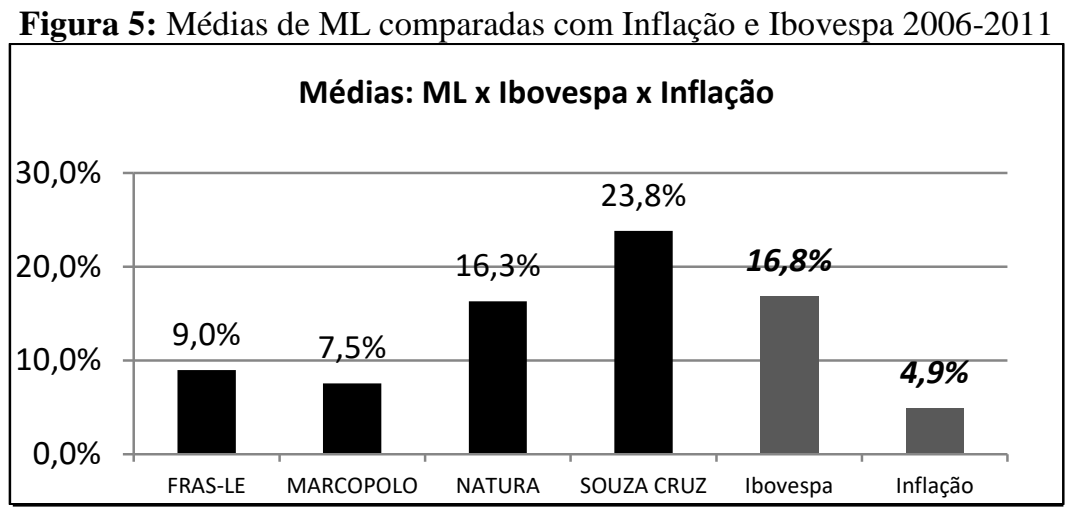

Fonte: elaborado pelos autores

Outro comparativo foi com a inflação do período, mais precisamente a "inflação de preços ao consumidor" (IPEA, 2013), que representou uma média de 4,9\%, com desvio padrão de $1,2 \%$. Neste quesito, todas as rentabilidades de ML média das empresas ficaram acima da inflação. Chama atenção que nem mesmo a ML de 5,3\% apurada na Marcopolo em 2008, o menor dos índices individuais de rentabilidade anual identificado entre as quatro empresas, ficou abaixo do índice médio da inflação dos seis anos.

\section{CONSIDERAÇÕES FINAIS}

Cada vez mais fica evidente que o desenvolvimento das empresas e dos países em que elas estão instaladas depende fundamentalmente do desenvolvimento tecnológico e da inovação. Quando são analisados os dados de investimentos em tecnologia e pesquisa dos países que estão se destacando em termos de desenvolvimento econômico, é claramente perceptível que estes vêm dando prioridade a estas áreas, com elevados investimentos desde a educação básica até a formação de pesquisadores.

No Brasil, embora alguns números demonstrem que está ocorrendo uma melhora em termos de indicadores de inovação, percebe-se a existência de um amplo espaço para evoluir. As áreas de $\mathrm{P} \& \mathrm{D}$ nas empresas ainda são restritas a grandes corporações, na sua maioria financiadas por capital estrangeiro. O governo brasileiro está buscando contribuir para que esta quase inércia de desenvolvimento tecnológico nacional coloque o Brasil, pelo menos, em nível idêntico de desenvolvimento tecnológico de outros países emergentes. 
Medidas governamentais, relacionadas principalmente às importações de tecnologia, linhas de financiamento específicas e incentivos fiscais, vêm sendo adotadas nas últimas décadas para que a inovação leve o país a novos patamares econômicos mundiais. E foi justamente a necessidade de compreender o comportamento econômico das empresas brasileiras que estão usando os incentivos fiscais que levou os autores a realizarem o presente estudo.

Assim, o objetivo desta pesquisa foi o de verificar e analisar qual o comportamento de alguns índices econômico-financeiros, especialmente do faturamento e da lucratividade, nas empresas de capital aberto que utilizaram o incentivo da Lei do Bem (Lei ${ }^{\circ}$ 1.196/2005) ininterruptamente, desde sua entrada em vigor no ano de 2006, até 2011, ano em que ocorreu a mais recente divulgação da listagem das empresas participantes.

É importante destacar que, embora a quantidade de empresas que utilizaram este benefício fiscal seja elevada (no mais recente relatório divulgado constam 767 empresas), apenas quatro empresas estavam aptas a serem analisadas por atenderem aos critérios de seleção definidos para este estudo. Os resultados indicam que essas quatro empresas, de um modo geral, apresentam variações positivas em seu faturamento no período analisado. Além disso, utilizando como critério a Margem Líquida (ML), foram identificados índices positivos de lucratividade em todas as empresas, embora fossem percebidas algumas variações entre as empresas quando estas foram analisadas individualmente.

Para corroborar com estes achados, os índices das empresas foram comparados com dois indicadores externos: a inflação e o Ibovespa, ambos do mesmo período (2006-2011). Quando comparados os índices médios de rentabilidade das empresas com a inflação, os primeiros se apresentaram superiores. Já quando comparados com o Ibovespa, apenas uma das empresas demonstrou melhor rentabilidade média, embora uma segunda tenha ficado com índices bem próximos a ele.

Como sugestão para estudos futuros, poderiam ser realizadas análises comparativas entre empresas beneficiárias dos incentivos fiscais com o desempenho do setor em que elas estão inseridas, ou ainda, comparar indicadores entre as empresas que usaram os incentivos fiscais com outras que não utilizaram. Além disso, outra sugestão é realizar um estudo com períodos maiores, englobando uma análise do comportamento dos indicadores dessas empresas antes de se utilizarem dos incentivos. 
A limitação do estudo reside no fato de que os resultados positivos encontrados entre as empresas que utilizaram o referido benefício podem não ter uma relação causal com inovação, ou seja, não se pode afirmar que os indicadores encontrados foram motivados pela inovação. É possível que estes advenham de outros fatores, como por exemplo, de um contexto econômico favorável.

Para concluir, este estudo não teve a pretensão de analisar se realmente todas as empresas que se utilizaram desse incentivo oferecido pelo governo realmente são empresas que inovaram. Apenas partiu-se do pressuposto que, pelo fato de terem se utilizado dos incentivos, atenderam as exigências legais para tal enquadramento, de acordo com o que expõe a legislação, baseada no Decreto n ${ }^{\circ}$ 5.798/2006, em seu Art. $2^{\circ}$ : inovação tecnológica é a concepção de novo produto ou processo de fabricação, bem como a agregação de novas funcionalidades ou características ao produto ou processo que implique em melhorias incrementais e efetivo ganho de qualidade ou produtividade, resultando em uma maior competitividade no mercado.

\section{REFERÊNCIAS}

Albuquerque, E. M. ; Simões, R.; Baessa, A.; Campolina, B.; Silva, L.. (2002) A Distribuição Espacial da Produção Científica e Tecnológica Brasileira: uma Descrição de Estatísticas de Produção Local de Patentes e Artigos Científicos. RBI - Revista Brasileira de Inovação, v. 1, n. 2, p. 225-251, ago. ISSN 2178-2822. Disponível em:

<http://www.ige.unicamp.br/ojs/index.php/rbi/article/view/244>. Acesso em: 16 jun. 2013.

Arbache, J. S.. (2005) Inovações tecnológicas e exportações afetam o tamanho e produtividade das firmas manufatureiras?: evidências para o Brasil. In: DE NEGRI, J.A.; SALERNO, M. S.(Org) Inovações, padrões tecnológicos e desempenho das firmas industriais brasileiras. Brasilia: IPEA.

Abdi - Agência Brasileira de Desenvolvimento Industrial. (2009) Estudos Setoriais de Inovação: Empresas Líderes na Indústria Brasileira.. Disponível em: 〈www.abdi.com.br〉. Acesso em: 23 mai. 2013.

Barros, A.; Lehfeld, N. A. S. (2007) Fundamentos de Metodologia Científica. 3. ed. São Paulo: Pearson Prentice Hall.

Bm\&Fbovespa - Bolsa de Valores, Mercadorias e Futuros. (2013) Disponível em: <http://www.bmfbovespa.com.br>. Acesso em: 24 mai. 2013. 
Braga, H. C.; Willmore, L. N.. (1990) As importações e o esforço tecnológico: uma análise de seus determinantes em empresas brasileiras. Revista Brasileira de Economia. Rio de Janeiro, v. 44, n. 2, p. 131-155, abr./jun.

Brasil. Decreto n 5.798 , de 7 de junho de 2006. DOU de 08.06.2006. Disponível em:< http://www.planalto.gov.br/ccivil_03/_Ato2004-2006/2006/Decreto/D5798.htm>. Acesso em: 22 jun. 2013.

Lei no 9.991, de 24 de julho de 2000. DOU de 25.07.2000. Disponível em:< http://www.planalto.gov.br/ccivil_03/Leis/L9991.htm>. Acesso em: 22 jun. 2013.

Lei $\mathrm{n}^{\mathrm{o}}$ 10.973, de 02 de dezembro de 2004. DOU de 03.13.2004. Disponível em:< https://www.planalto.gov.br/ccivil_03/_Ato2004-2006/2004/Lei/L10.973.htm>. Acesso em: 22 jun. 2013.

Lei $\mathrm{n}^{\circ}$ 11.196, de 21 de novembro de 2005. DOU de 22.11.2005. Disponível em:< https://www.planalto.gov.br/ccivil_03/_Ato2004-2006/2005/Lei/L11196.htm >. Acesso em: 22 jun. 2013.

Camargo, C. (2009) Planejamento Financeiro. 3. ed. Curitiba: Ibpex.

Cooper, D. R.; Schindler, P. S. (2003) Métodos de pesquisa em administração. 7. ed. Porto Alegre: Bookman.

Cruz, C. H. B.; Mello, L. de. (2006) Boosting Innovation performance in Brazil. Working Paper. Paris, n. 532.

Dahlman, C. J.; Frischtak, C. R. (1993) National Systems Supporting Technical Advance in Industry: The Brazilian Experience. Cap. 13 In: National Innovation Systems: A Comparative Analysis. Nelson, R.R.. Coordination. Oxford University Press; New York, Oxford.

Diehl, A. A.; Tatim, D. C. (2004) Pesquisa em ciências sociais aplicadas: métodos e técnicas. São Paulo: Pearson.

Dosi, G. (1982) The nature of the innovative process. Technical change and economic theory. London, Pinter.

Eckert, A. (2013) Teoria da Contabilidade. 2. Ed. São Paulo: Edipro.

Ergas, H. (1984) Why Do Some Countries Innovate More than Others? Brussels: Centre for European Policy Studies.

Fras-Le S/A. (2013) Institucional, empresa. Disponível em:

<http://www.frasle.com.br/pt/institutional> Acesso em: 05 jun. 2013.

Furman, J.L.; Porter, M.E.; Stern, S. (2002) The determinants of national innovative capacity. Research Policy, Volume 31, Issue 6, Pages 899-933 August. http://dx.doi.org/10.1016/S0048-7333(01)00152-4

Gitman, L. J. (1997) Princípios de administração financeira. 7. ed. São Paulo: Harbra. 
Godoy, A. (1995) Introdução à pesquisa qualitativa e suas possibilidade. Revista de Administração de Empresas. São Paulo, v. 35, n. 2, p. 57-63, mar./abr..

http://dx.doi.org/10.1590/S0034-75901995000200008

Ipea. (2013) Inflação dos preços ao consumidor. Disponível em:

<http://www.brasil.gov.br/sobre/economia/indicadores/precos12_ipcag12/indicadorview> Acesso em: 26 jun. 2013.

Iudícibus, S. (2009) Análise de balanços. 10.ed. São Paulo: Atlas.

Kannebley Júnior. S.; Porto, G. S.; Pazzelo, E. T.. (2003) Características das empresas inovadoras no Brasil: uma análise empírica a partir da Pintec. In: Encontro Nacional de Economia, 31. Porto Seguro. Anais... Porto Seguro: ANPEC.

Lundvall, B.A. (1992) National systems of innovation: towards a theory of innovation and interactive learning. London: Pinter Publishers, . (2002) Innovation, Growth and Social Cohesion: the Danish Model.

Chetenham, Uk: Edward Elgar,.

Mansfield, E. (1974) Technology and technological change. In: Dunning, J. H. (Ed.), Economic analysis and the multinational enterprise. London: George Allen \& Unwin Ltd., p.147-183,.

Marcopolo. (2013) Nossa História. Disponível em:

<http://www.marcopolo.com.br/website/2011/marcopolo/pt/a_marcopolo/empresa> Acesso em: 20 mai. 2013.

Marion, J. C. (2012) Análise das Demonstrações Contábeis: contabilidade empresarial. 7. ed. São Paulo: Atlas.

Martins, G. A.; Theóphilo, C. R.. (2007) Metodologia da investigação científica para ciências sociais aplicadas. São Paulo: Atlas.

Matarazzo, D. C. (2003) Análise financeira de balanços: abordagem básica e gerencial. 6.ed. São Paulo: Atlas.

Mascarenhas, S. A.. (2012) Metodologia Científica. São Paulo: Pearson Education do Brasil.

Maximiano, A. C. A. (1980) Administração do processo de inovação tecnológica. São Paulo: Atlas.

Mcti - Ministério da Ciência, Tecnologia e Inovação. (2013) Relatório Anual da Lei 1.196/2005 - Ano base 2006 a 2011. Disponível em:

<http://www.mcti.gov.br/index.php/content/view/8563/Informacoes_Gerais.html >. Acesso em: 29 mai. 2013.

Motohashi, K. (1998) Innovation strategy and business performance of Japanese manufacturing firms. Economics of Innovation and New Technology, v. 7, n. 1, p. 27-52,. 
Natura. (2013) Sobre a Natura - Empresa. Disponível em:

$<$ http://scf.natura.net/Conteudo/Default.aspx?MenuStructure $=5 \&$ MenuItem=1 $>$ Acesso em: 21 mai. 2013.

Nelson, R. (2000) Why do firms differ, and how does it matter? In: Nelson, R. (Ed.), The sources of economic growth. Cambridge: Havard University Press,.

Ocde - Organização para a Cooperação e Desenvolvimento Econômico. (2007) Manual de Oslo. Diretrizes para a coleta e interpretação de dados sobre Inovação. 3. ed. Tradução

FINEP,. Disponível em: <www.finep.org.br> Acesso em 23 mai. 2013.

Oliveira, M. R. (2002) Tendências das Atuais Políticas de Ciência e Tecnologia:

Ressignificações no Espaço Universitário. 25 Reunião Anual da Associação Nacional de PósGraduação e Pesquisa em Educação. Caxambu,. Disponível em:

$<$ http://www.anped.org.br/reunioes/25/excedentes25/marlizerubinoliveirat11.rtf > . Acesso em: 22 jun. 2013.

Reis, D. R. (2008) Gestão da Inovação Tecnológica. 2. ed. Barueri, SP: Manole.

Rodriguez, A; Dahlman, C.;Salmi, J. (2008) Conhecimento e Inovação para a

Competitividade. Banco Mundial. Brasília, CNI.

Rogers, E. M. . (1995) Diffusion of innovations. $4^{\mathrm{a}}$ ed. The Free Press.

Schumpeter, J. (1982) Teoria do Desenvolvimento Econômico, trad. Maria Sílvia Possas. São Paulo: Editora Abril.

Silva, C. G.; Melo, L. C. P. (2001) (Coord). Ciência, Tecnologia e Inovação: Desafio para a Sociedade Brasileira - Livro Verde. Brasília: Ministério da Ciência e Tecnologia/Academia Brasileira de Ciências..

Souza Cruz. (2013) Quem somos. Disponível em: <http://www.souzacruz.com.br/> Acesso em: 15 mai. 2013.

Teece, D. J.; Pisano, G.; Schuen, A. (1997) Dynamic Capabilities and Strategic Management. Strategic Management Journal. Vol 18:7, 509-533.

Utterback, J. M.. (1971) The process of technological innovation within the firm. Academy of Management Journal, v. 14, n. 1, p.75-88,.

Turchi, L. (2013) Empresários e Pesquisadores: avaliação da interação universidade e empresas. Radar : tecnologia, produção e comércio exterior. № 26 - p. 15-23. Ipea: Brasilia. Disponível em:

$<$ http://www.ipea.gov.br/portal/index.php?option=com_alphacontent\&view=alphacontent\&It emid=80> Acesso em: 26 jun. 2013.

Zawislak, P. A.. (2008) In: Tidd, J; Bessant, J; Pavitt, K. Gestão da Inovação. Porto Alegre, Bookman, 